\title{
Avaliação de métodos para determinação de cloro residual livre em águas de abastecimento público
}

\author{
Evaluation of methods for determination free available chlorine in \\ public water supply
}

\author{
Samara Silva Soares ${ }^{1}$, Poliana Nascimento Arruda ${ }^{2}$; Germán Sanz Lobón³; Paulo Sérgio Scalize ${ }^{4}$
}

\begin{abstract}
Resumo
A etapa de desinfecção no tratamento de água é de grande importância na garantia de água potável com qualidade sanitária. A cloração é o método mais utilizado nesse processo, em que propicia a inativação e/ou destruição dos microrganismos patogênicos. Para medição do seu teor residual na água distribuída à população, o método DPD colorimétrico é o mais utilizado. Dessa forma, essa pesquisa objetivou avaliar o método utilizando dois aparelhos, visual e digital com DPD em duas formas, pó e pastilha. Análises dos parâmetros $\mathrm{pH}$, turbidez, fluoreto e condutividade elétrica, coliformes totais e E. coli também foram realizadas com a finalidade de verificar uma correlação. Nessa pesquisa foram coletadas 40 amostras em residências distribuídas em 6 bairros de 3 diferentes regiões do município de GoiâniaGO. Verificou-se que os valores encontrados para o DPD em pó foram superiores a forma de pastilha e que os resultados do equipamento digital foram inferiores ao disco comparador. Foi encontrada influência da turbidez sobre os resultados de cloro residual livre bem como uma relação inversa entre o flúor e condutividade elétrica.
\end{abstract}

Palavras-chave: Cloro residual livre. DPD. Disco colorimétrico. Clorímetro digital.

\begin{abstract}
To assurance the drinking water quality, the disinfecting has to be guaranteed. In this sense, chlorination is the most widely used method, which promotes the inactivation and/or destruction of pathogenic microorganisms. The analytic methods more common for free available chlorine in drinking water are based on the DPD colorimetric method. In this way, the main core of this research is to compare the results obtained between two devices that can use two types reagents: visual and digital equipments; and powder and tablet reagents. Moreover, was analyzed whatever correlation between the others measured parameters: $\mathrm{pH}$, turbidity, electric conductivity, fluoride, total coliforms and Escherichia coli. Were collected 40 samples in particular homes, which were distributed in six districts of three different areas of the city of Goiânia (Goiás, Brazil). The results were that the powder reagent had higher values than tablet ones, and that the measures of the digital equipment were lower than the visual disk. By other hand, was found one linear correlation between turbidity and the free available chlorine, and one soft inverse relationship between the fluorine and the electric conductivity.
\end{abstract}

Keywords: Free available chlorine. DPD. Visual disk. Pocket colorimeter.

\footnotetext{
${ }^{1}$ Graduanda em Engenharia Ambiental e Sanitária, Universidade Federal de Goiás; samara.y8@gmail.com.

${ }^{2}$ Mestranda em Engenharia do Meio Ambiente, Universidade Federal de Goiás; arrudaifg@hotmail.com.

${ }^{3}$ Doutor em Tecnologia do Meio Ambiente, Pesquisador na Universidade Federal de Goiás; manger84@gmail.com.

${ }^{4}$ Prof. Dr., Escola de Engenharia Civil e Ambiental, Universidade Federal de Goiás; pscalize.ufg@gmail.com.
} 


\section{Introdução}

Para que a água tratada seja considerada potável, é necessário que ela possua características físicas, químicas e biológicas que não afetem a saúde da população, sendo condizentes com o exigido pela legislação referente à potabilidade da água. Entre os parâmetros podem-se destacar os organismos do grupo coliformes, que indica a qualidade sanitária da água produzida. A etapa responsável pela inativação ou destruição desses microrganismos patogênicos é a desinfecção, que ocorre por intermédio de agentes físicos e/ou químicos. No Brasil sob o regime da Portaria no 2914 de 2011 (BRASIL, 2011), a desinfecção é obrigatória a todos os sistemas de fornecimento de água para abastecimento público, visando à proteção da saúde dos consumidores.

$\mathrm{O}$ cloro $\left(\mathrm{Cl}_{2}\right)$ é o agente químico mais utilizado para a desinfecção, sendo empregado em larga escala nas estações de tratamento de água (DANIEL et al., 2001). O mesmo tem sido utilizado comercialmente sob três formas: líquido, sólido ou gasoso. Em contato com a água, o cloro gasoso se hidrolisa rapidamente para formar os íons hidrogênio, cloreto e o ácido hipocloroso. Este ácido se dissocia gerando íons hidrogênio e hipoclorito. O ácido hipocloroso e o íon hipoclorito são os principais responsáveis pela oxidação da matéria orgânica indesejada e a soma de suas concentrações é conhecida como cloro residual livre, que varia com a temperatura e pH da água, sendo de importância vital na inibição do crescimento bacteriano (AMERICAN PUBLIC HEALTH ASSOCIATION; AMERICAN WATER WORKS ASSOCIATION; WATER ENVIRONMENT FEDERATION, 2005).

Os principais mecanismos de ação de desinfetantes químicos como o cloro para a inativação de organismos patogênicos é a destruição ou desarranjo estrutural da organização celular por ataque aos principais constituintes da célula, interferência no metabolismo energético, tornando as enzimas não funcionais e interferência na biossíntese e no crescimento, pelo prejuízo à síntese de proteínas, ácidos nucleicos, coenzimas ou parede celular (DANIEL et al., 2001).

A reação do cloro com alguns compostos orgânicos leva à formação de subprodutos como os trihalometanos que podem ter efeitos negativos à saúde humana. No entanto, a substituição do cloro por outro desinfetante no tratamento da água pode trazer mais riscos do que benefícios. A diminuição da incidência de doenças transmissíveis pela água somente foi alcançada com a difusão do emprego da técnica da cloração, possibilitando uma melhora na qualidade de vida e diminuição da mortalidade infantil por doenças entéricas (DANIEL et al., 2001; MEYER, 1994). Portanto, a desinfecção não deve ser comprometida para que seja controlada a geração de subprodutos da cloração (WORLD HEALTH ORGANIZATION, 2011).

Além do processo de desinfecção, a Portaria $n^{\circ}$ 2914 (BRASIL, 2011) exige a presença do residual de cloro livre com concentração mínima de 0,20 $\mathrm{mg} / \mathrm{L}$ em todo o sistema de distribuição, a fim de garantir a qualidade microbiológica da água. Segundo Helbling e Vanbriesen (2007), a demanda de cloro pode ser um indicador substituto para a contaminação microbiana do sistema de distribuição de água e sua utilidade pode ser reforçada em locais do sistema de distribuição de água que mantêm um maior residual de cloro livre.

A determinação de cloro residual pode ser feita por vários métodos, dentre os quais podem ser citados o iodométrico, o amperométrico e o $N, N$-dietil- $p$-fenilendiamina (DPD). O método da ortotolidina, não listado anteriormente, foi provavelmente o mais usado, sendo excluído da $15^{\mathrm{a}}$ edição do Standard Methods por tratar-se de uma substância cancerígena.

O método iodométrico é adequado para a medição das concentrações de cloro total superior a $1,0 \mathrm{mg} / \mathrm{L}$. O método de titulação amperométrica é considerado o método mais preciso para a determinação de cloro livre ou combinado, pois ele é pouco afetado por agentes oxidantes comuns, 
variações de temperatura, turbidez e cor, mas não é tão simples como os métodos colorimétricos, requerendo maior habilidade do operador para obter a melhor confiabilidade (APHA; AWWA; WEF, 2005).

O método DPD colorimétrico é operacionalmente mais simples para a determinação de cloro residual livre, quando comparado a titulação amperométrica. Neste método, o composto (DPD) é usado como indicador. A cor rosada característica desenvolve-se em águas que não contêm iodeto e indica a presença de cloro residual livre. O DPD é oxidado por cloro livre, resultando numa solução com uma intensidade de cor proporcional à concentração de cloro livre. A medida da concentração pode ser realizada utilizando o disco colorimétrico ou o clorímetro digital. O primeiro emprega a comparação visual como método de análise e o segundo, a absorção da solução resultante é medida por fotometria (HELBLING; VANBRIESEN, 2007).

As desvantagens desse método estão principalmente relacionadas aos interferentes, tanto as espécies cloradas, que oxidam o reagente DPD, quanto à presença de manganês e de altas concentrações de clorito. Parâmetros como cor e turbidez podem interferir em todos os procedimentos colorimétricos, sendo necessário compensar usando uma amostra de branco (APHA; AWWA; WEF, 2005).

Existem outros parâmetros que podem causar interferências nos resultados de cloro residual livre como matéria orgânica e ferro (DI BERNARDO, 2005). Estudos foram realizados com intuito de obter as relações entre alguns parâmetros e seus reflexos sob a o método colorimétrico. A presença de ferro e manganês na água afeta a cloração, pois se o $\mathrm{pH}$ for elevado o bastante para que haja a formação de hidróxidos e a quantidade de cloro presente seja suficiente, as formas reduzidas desses metais serão oxidadas às suas formas de hidróxidos insolúveis (MEYER, 1994).

Em pesquisa realizada por Souza, Sartori e Daniel
(2000) com o objetivo de analisar a interferência da cor e da turbidez na eficiência da desinfecção, concluíram que para valores baixos de cor e turbidez, tem-se maior porcentagem de remoção de E. coli quando comparado a valores altos de cor e turbidez, no que induzem menor eficiência na desinfecção, resultando em maior consumo de cloro.

Conforme Saad et al. (2005), após compararem vários reagentes para a determinação de cloro livre disponível e cloro total disponível por injeção de fluxo (FI) para métodos espectrofotométricos, concluíram que o reagente que rendeu o sinal mais sensível (limite de detecção de $0,02 \mathrm{mg} / \mathrm{L}$ ) foi o ABTS (2,2-azino-bis-3 etilbenzotiazolina6-sulfonato), sofrendo menos interferência por manganês, zinco e cobre, mas houve interferência de cloro combinado. Neste caso é fortemente recomendado o reagente SYR (siringaldazina), pois foi o menos afetado pelo cloro combinado. No entanto, o método DPD não foi analisado devido à sujeição de interferências de cloro combinado e por não ser linear quando a concentração de cloro residual é superior a 1,0 mg/L, não sendo adequado para a determinação de cloro de alta concentração em processos industriais de cloração que contem nível significativo de cloro combinado.

Um estudo comparativo entre três métodos comuns na determinação de cloro residual, realizado por Wilde (1991), utilizando amostras de água do rio Savannah na cidade de Aiken, localizada no estado norte-americano da Carolina do Sul, concluiu que o método DPD e o método de titulação amperométrica produzem resultados estatisticamente semelhantes. O método DPD por ser mais simples, fornecer resultados rápidos e ser adequado para medições em campo e laboratório, foi proposto para o monitoramento da água avaliada. Noll, Oliveira e Pescador (2000) também compararam dois métodos para a determinação de cloro residual, com a utilização do reagente ortotolidina e do DPD, encontrando melhores resultados com esse último.

Atualmente o mercado disponibiliza o DPD na 
forma sólida (pó e pastilha) e líquida. Dessa forma, o presente trabalho teve como objetivo comparar os resultados do teor de cloro livre obtidos pela leitura de amostras de água tratada, coletadas na rede de distribuição, utilizando o método DPD empregando reagente em pó e pastilha com medições no disco colorimétrico e no clorímetro digital, a fim de comparar a melhor combinação para uso em monitoramento de água no alcance de melhores resultados, além de verificar possíveis interferências de turbidez, $\mathrm{pH}$, condutividade elétrica (CE) e fluoreto sobre os resultados de cloro residual livre.

\section{Metodologia}

A área de estudo compreende bairros da Região Norte, Noroeste e Leste do município de Goiânia, abastecidos pela Estação de Tratamento de Água
(ETA) Jaime Câmara e pela ETA Meia Ponte.

Para a realização do experimento foram coletadas 40 amostras aleatoriamente (sem levar em consideração a distância a partir do ponto de cloração), no período de 15 a 31 de julho de 2014, distribuídas em seis setores (Figura 1), sendo 5 no Setor Parque Tremendão (Figura 2a), 10 no Setor São Judas Tadeu (Figura 2b), 15 no Setor Leste Vila Nova (Figura 2c), 6 no Setor Parque Industrial (Figura 2d), 1 no Setor Bairro Feliz (Figura 2e) 3 no Setor Leste Universitário (Figura 2f). O Setor Parque Tremendão é abastecido pela água tratada na ETA Meia Ponte e, os demais abastecidos por água advinda da ETA Jaime Câmara. As 40 amostras foram consideradas como sendo um único extrato, de onde foram realizadas as considerações.

Figura 1 - Área de estudo contendo os setores onde se coletou as amostras de água.
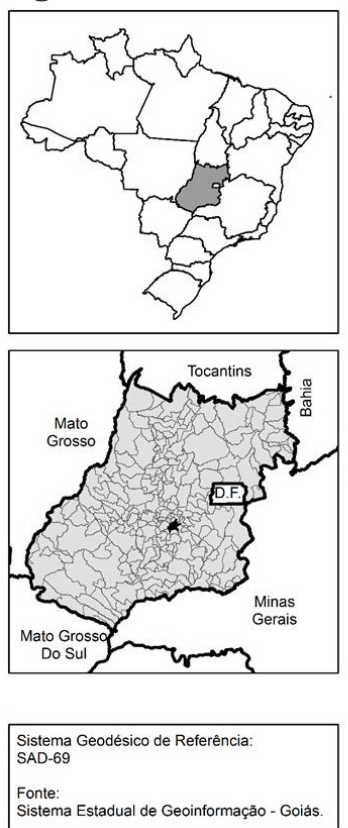

Fonte: o próprio autor
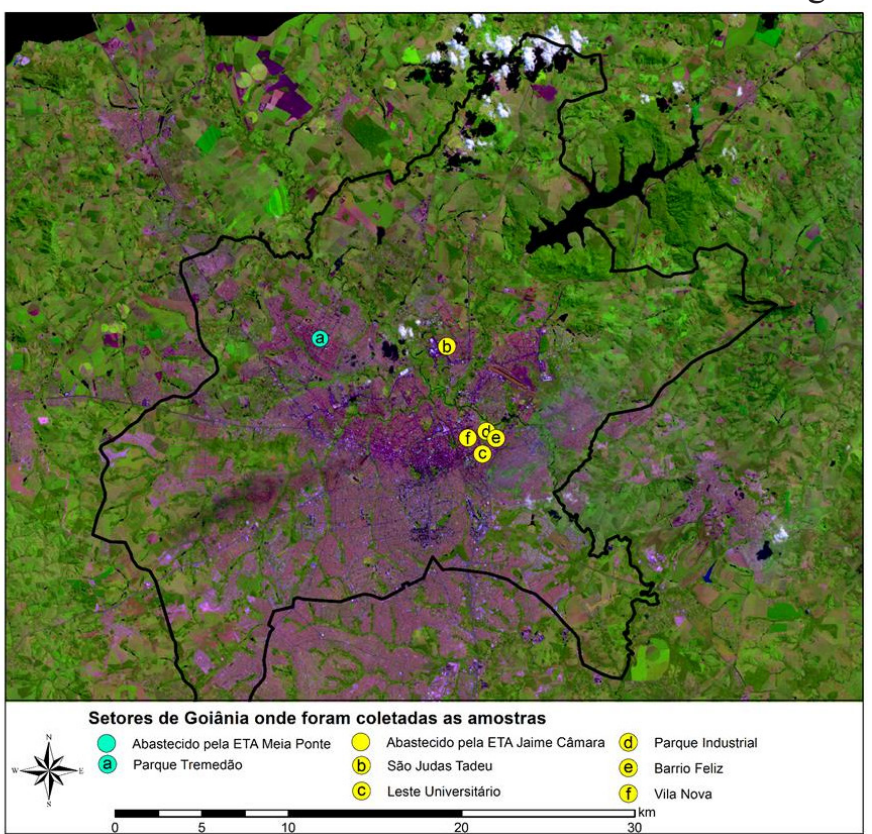

As coletas foram realizadas conforme manual da Companhia Ambiental do Estado de São Paulo (2011), ocorrendo diretamente em torneiras que recebiam água do abastecimento público, ou seja, sem passar por reservatórios domiciliares, para não comprometê-las por eventual consumo de cloro durante a reservação. A determinação do teor de cloro residual livre em cada amostra foi determinada imediatamente após a coleta. 
Figura 2 - Pontos de coletas distribuídos pela cidade de Goiânia, sendo 5 no Setor Parque Tremendão (Figura 2a), 10 no Setor São Judas Tadeu (Figura 2b), 15 no Setor Leste Vila Nova (Figura 2c), 6 no Setor Parque Industrial (Figura 2d), 1 no Setor Bairro Feliz (Figura 2e) 3 no Setor Leste Universitário (Figura 2f).
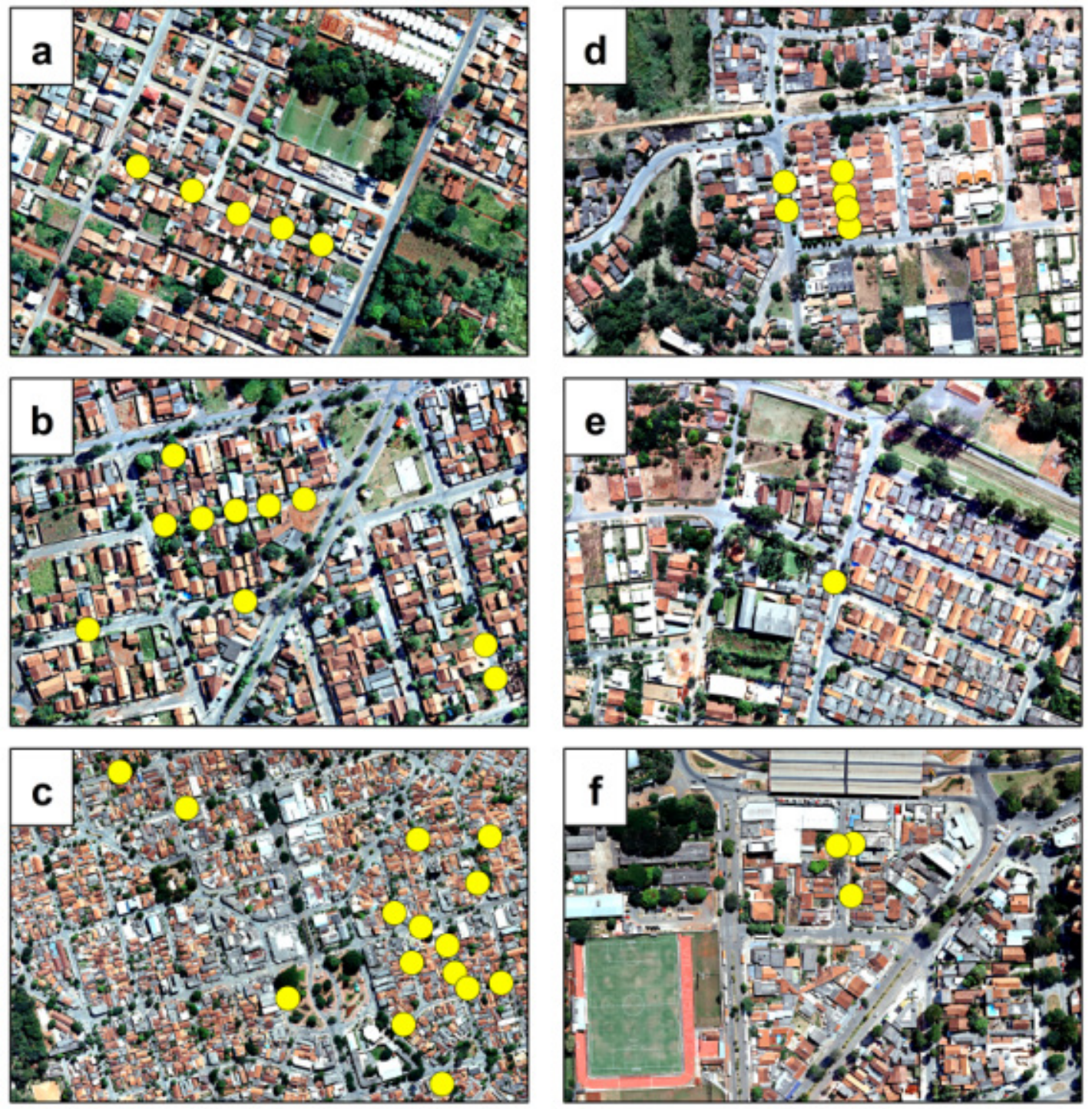

Fonte: o próprio autor

As determinações do cloro residual livre foram realizadas utilizando um comparador visual, da marca Dellab, provido de disco colorimétrico com intervalo de medição entre 0 e $3,5 \mathrm{mg} / \mathrm{L}$ (Figura 3a) e um clorímetro digital portátil, da marca Hach (Figura 3b), que trabalha com comprimento de onda de $528 \mathrm{~nm}$ e possui precisão de $\pm 0,02 \mathrm{mg} / \mathrm{L}$, capaz de medir concentrações entre 0 e 4,5 mg/L utilizando o reagente DPD em pó ou pastilha. Ambas as metodologias se baseiam em testes colorimétricos aplicando o método DPD colorimétrico, método 4500-Cl G (APHA; AWWA; WEF, 2005). Simultaneamente às coletas de amostras para análise de cloro foram procedidas amostragens para determinação dos parâmetros turbidez, pH, CE, flúor, coliformes totais e E. coli, sendo as análises realizadas conforme Standard Methods (APHA; AWWA; WEF, 2005). 
Figura 3 - Equipamentos utilizados na pesquisa. Conjunto com disco colorimétrico, marca Del Lab (a) e Clorímetro Digital Portátil marca Hach (b).
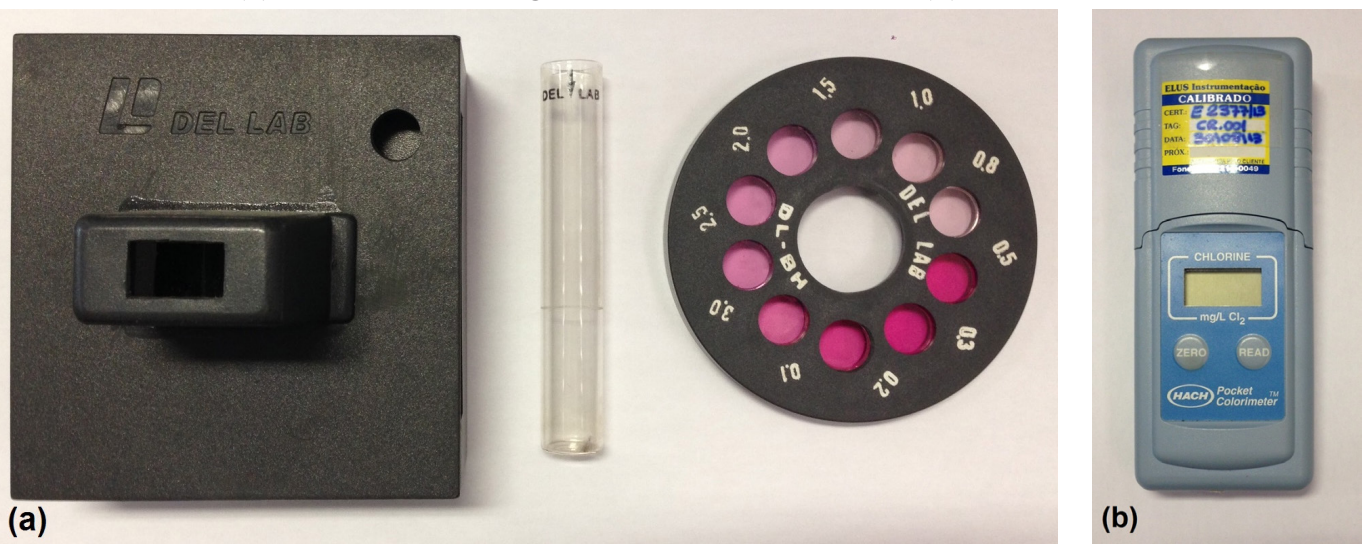

Fonte: o próprio autor

Os resultados obtidos das análises físico-químicas foram tratados estatisticamente com XLSTAT, obtendo-se os estatísticos: média, mediana, desvio padrão e o coeficiente de variação, dos quais foram construídos gráficos do tipo boxplot, com um intervalo de confiança de $95 \%$, possibilitando verificar os valores discrepantes de cada parâmetro analisado. Complementando o estudo, foi realizado um tratamento estatístico através da correlação de
Spearman (R) entre os parâmetros cloro residual livre (obtido nos diferentes métodos); a turbidez; o $\mathrm{pH}$; a CE e o fluoreto.

\section{Resultados e Discussão}

Na Figura 4 são apresentados os teores de cloro residual livre lidos nas 40 amostras, com a aplicação dos 4 métodos empregados, distribuídas por dia de coleta e seu respectivo setor.

Figura 4 - Variação da concentração de cloro residual livre obtida para os diferentes reagentes e equipamentos utilizados.

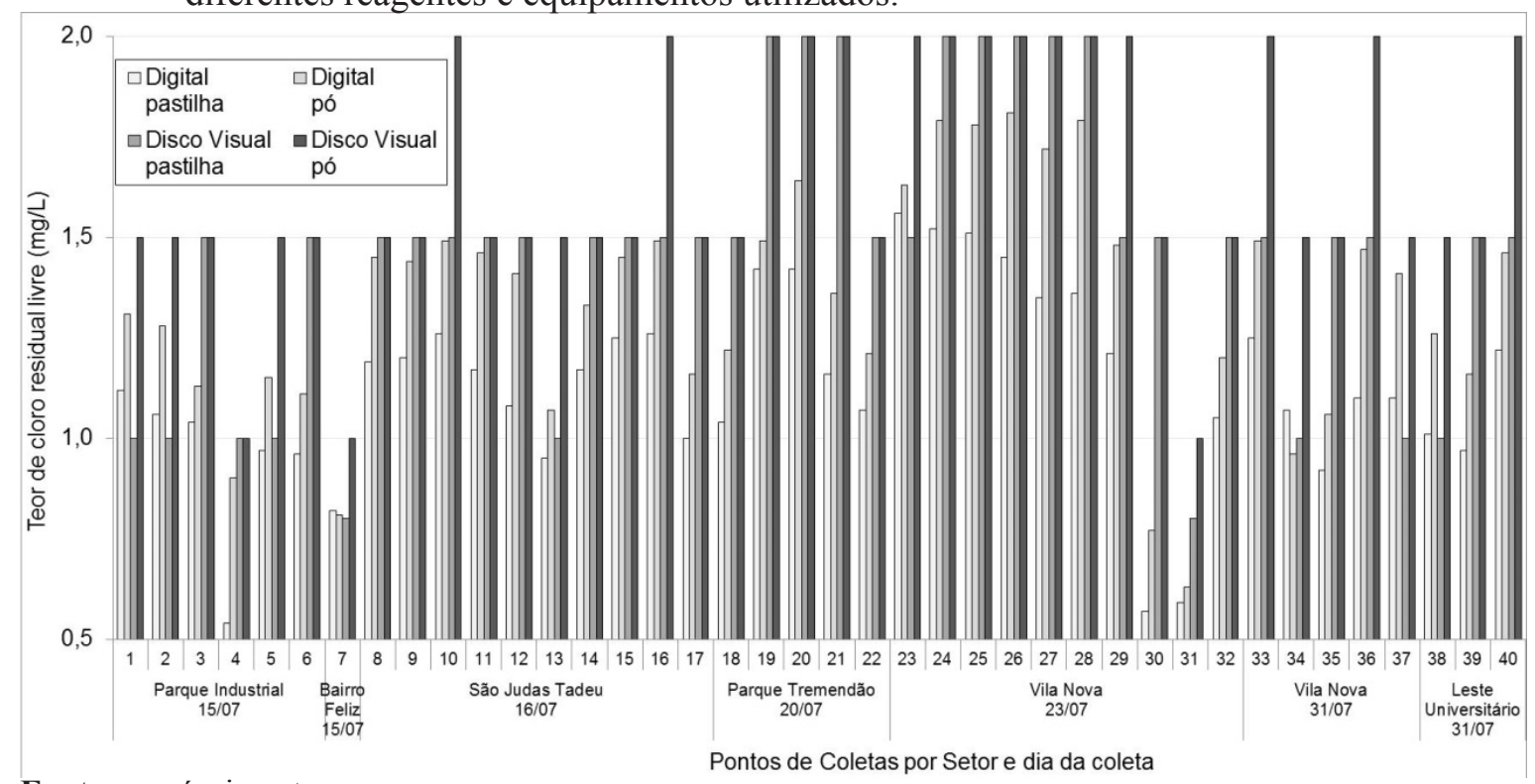

Fonte: o próprio autor 
Pode ser observado que os valores de cloro residual livre detectados nas amostras coletadas variaram de 0,54 mg/L a 2,0 mg/L (Figura 4 e Figura 5a). O coeficiente de variação $(\mathrm{CV})$ calculado para os resultados obtidos em cada amostra com o emprego dos diferentes métodos (desconsiderando um valor atípico de $42,8 \%$ ) variou de $8,1 \%$ a $26,1 \%$, podendo ser observado no Boxplot da Figura 5b. Ao verificar as recomendações da Portaria n²914/11 que dispõe sobre os padrões de potabilidade da água, todas as amostras satisfizeram às concentrações mínimas e máximas permissíveis de $0,2 \mathrm{mg} / \mathrm{L}$ e $2,0 \mathrm{mg} / \mathrm{L}$, respectivamente, sendo obrigatória a manutenção em toda a extensão do sistema de distribuição, incluindo reservatório e rede (BRASIL, 2011). Foi observada também uma diferença linear entre as médias dos resultados obtidos em cada método empregado (Figura 5a), apresentando um $\mathrm{R}^{2}$ de 0,994 . Os valores médios das leituras foram menores quando realizadas no equipamento digital com reagente em pastilha e pó, seguido dos resultados obtidos no equipamento disco colorimétrico com reagente em pastilha e em pó, respectivamente. Dessa forma, existe uma diferença entre os resultados médios variando de 10,5\% (Digital-pó e Disco Visual-pastilha) a 47,3\% (Digital-pastilha e Disco Visual-pó), com valores intermediários de 12,2\% (Disco Visual-pó e Disco Visual-pastilha), 18,8\% (Digital-pó e Digitalpastilha), 24,1 (Digital-pó e Disco Visual-pó) e 31,3\% (Digital-pastilha e Disco Visual-pastilha).

Figura 5 - Variação dos teores de cloro residual em função do método aplicado, bem como o desvio padrão e coeficiente de variação das médias dos resultados encontrados para cada amostra.
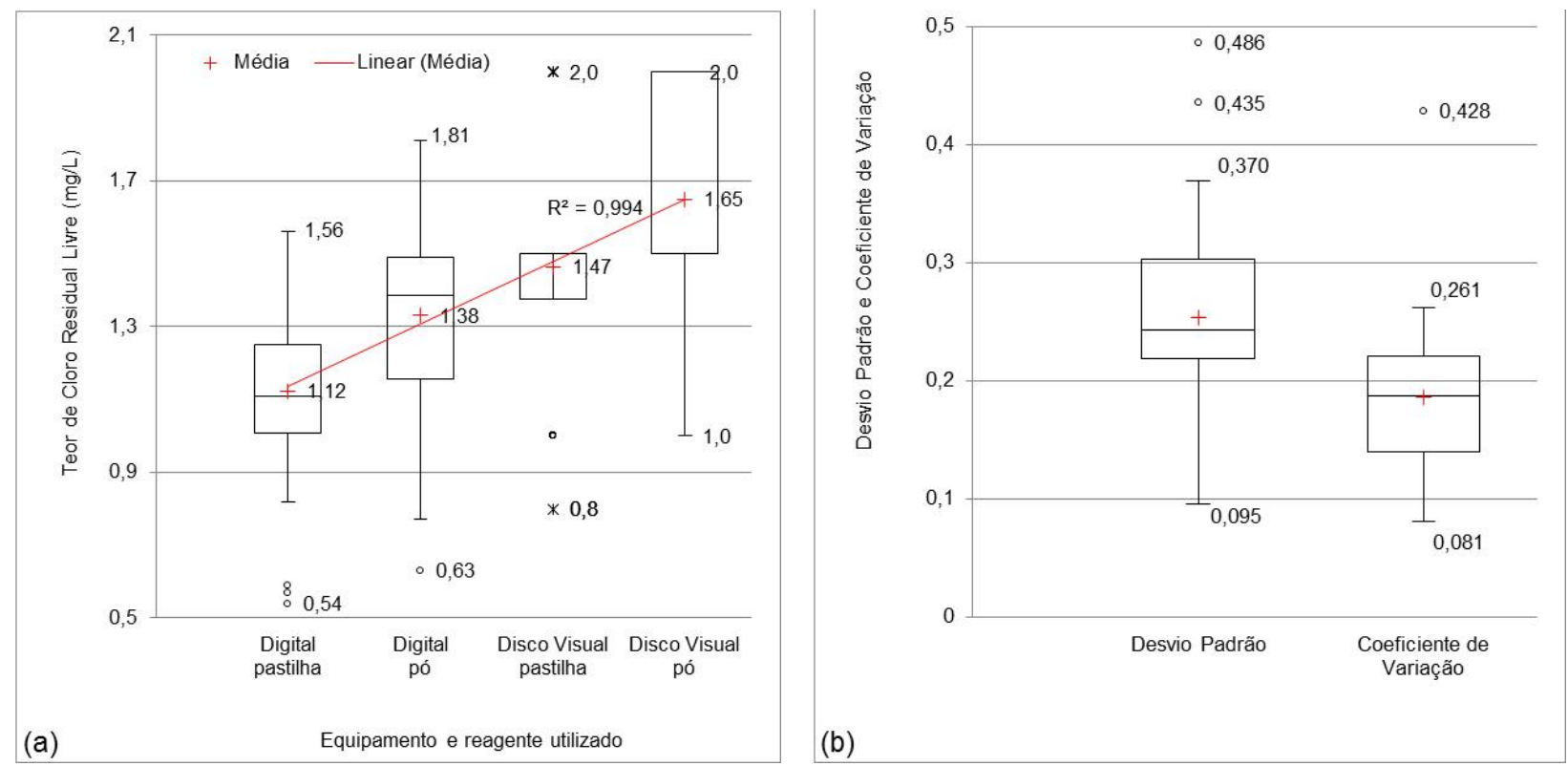

Fonte: o próprio autor

A matriz de correlação de Spearman (Tabela 1) permite visualizar os valores em negritos, que são diferentes de zero com um nível de significância alfa igual a 0,05. Observa-se uma correção entre a turbidez e as leituras de cloro residual livre, relacionadas como o equipamento digital independente do reagente utilizado, sendo que o mesmo não ocorre com a turbidez e as leituras de cloro residual livre realizada como disco colorimétrico. Assim, a turbidez influenciou nas análises como já foi descrito para o método 4500Cl.G DPD Colorimetric Method (APHA; AWWA; WEF, 2005). 
Além de isso, verificou-se a existência de uma relação inversa entre o flúor e condutividade elétrica (correlação de -0,5442). Esse fato também foi identificado em outras pesquisas em águas de manancial superficial, apresentando correlações semelhantes, estando entre -0,52 e -0,77 (CHIRKES; HEREDIA; CIRELLI, 2014; HORBE; OLIVEIRA, 2008). Nascimento e Alves (2014) consideraram a correlação de Spearman maior que 0,70 para definir as altas associações. O coeficiente $(\mathrm{R})$ varia de 1 a -1 , sendo que os valores mais próximos de -1 indicam forte correlação inversa, os valores próximos de 1 indicam forte correlação direta e valores próximos de 0 apresentam fraca correlação (ARAUJO; ZEILHOFER, 2011).

A hipóteses da correlação entre os fluoretos e a condutividade elétrica, está em função da natureza solúvel do fluoreto compondo parte dos sólidos totais dissolvidos além de sua elevada sensibilidade frente a temperatura. Além de isso, a condutividade também é um parâmetro dependente da temperatura, como mostra o método de análise, onde se devem padronizar as medições a uma temperatura de $20^{\circ} \mathrm{C}$. Em estudos desde a década de 70 com águas subterrâneas e termais é relatada a relação do teor de flúor com a temperatura, a profundidade e a natureza geológica do substrato (NORDSTROM; JENNE, 1977).

Tabela 1 - Matriz de correlação de Spearman.

\begin{tabular}{|c|c|c|c|c|c|c|c|c|}
\hline Variáveis & $\begin{array}{l}\text { Digital } \\
\text { pastilha }\end{array}$ & $\begin{array}{l}\text { Digital } \\
\text { pó }\end{array}$ & $\begin{array}{l}\text { Disco Visual } \\
\text { pastilha }\end{array}$ & $\begin{array}{c}\text { Disco } \\
\text { Visual } \\
\text { pó }\end{array}$ & Turbidez & $\mathrm{pH}$ & $\begin{array}{l}\text { Condutividade } \\
\text { Elétrica }\end{array}$ & Fluoreto \\
\hline Digital - pastilha & 1 & & & & & & & \\
\hline Digital - pó & 0,9545 & 1 & & & & & & \\
\hline Disco Visual - pastilha & 0,6874 & 0,7079 & 1 & & & & & \\
\hline Disco Visual - pó & 0,8237 & 0,8535 & 0,7388 & 1 & & & & \\
\hline Turbidez & 0,4056 & 0,3458 & 0,1950 & 0,2925 & 1 & & & \\
\hline $\mathrm{pH}$ & $-0,1508$ & $-0,1233$ & $-0,2973$ & $-0,1256$ & $-0,2782$ & 1 & & \\
\hline Condutividade Elétrica & 0,0423 & $-0,0437$ & $-0,2282$ & $-0,1631$ & 0,2082 & 0,1997 & 1 & \\
\hline Fluoreto & $-0,2084$ & $-0,1766$ & $-0,1920$ & 0,0147 & $-0,0926$ & 0,0334 & $-0,5442$ & 1 \\
\hline
\end{tabular}

Os valores em negrito são diferentes de 0 com um nível de significância alfa $=0,05$

Fonte: o próprio autor

De forma geral, quando se verifica que o residual de cloro livre presente na água distribuída a população, está dentro dos limites máximos e mínimos impostos pela norma vigente, entende-se que está dentro dos padrões de potabilidade. No entanto, pouco se faz para utilizar a quantidade necessária do produto químico utilizado para desinfecção sem consumir mais produtos do que o necessário. O ideal é que a água seja distribuída com o menor teor de cloro residual livre possível, atendendo o mínimo de $0,2 \mathrm{mg} / \mathrm{L}$ em qualquer ponto da rede e obedecendo os critérios na saída da distribuição, onde devem ser considerados parâmetros como tempo de contato, temperatura, residual livre de cloro e o pH da água (BRASIL, 2011).

Essa ausência de gestão pode influenciar nos gastos do desinfetante no momento da cloração. Isso, juntamente com os erros nas leituras, que podem não corresponder ao real teor de cloro presente na amostra de água, podem ampliar o seu consumo.

As variações da leitura de cada equipamento dependem de vários fatores e interferentes. Um 
deles pode estar relacionado à curva de calibração que cada empresa utilizou na fabricação de seu equipamento, principalmente nos discos comparadores, pois são construídos com lentes em escala de cores. Os equipamentos são fabricados para utilizarem os seus reagentes, comercializados pela própria empresa, sendo que qualquer alteração deve ser inserida nova curva de calibração no equipamento digital ou adequação do disco no caso do comparador colorimétrico. Além disso, os equipamentos digitais necessitam de calibração com relação ao seu funcionamento (absorbância, comprimento de onda, lâmpada, etc.), quanto aos discos comparadores, é necessária a verificação do desgaste das lentes em função do tempo (incidência solar, ressecamento, etc.). Outro fator, que influi principalmente na utilização do disco colorimétrico é a luminosidade e a aproximação entre o manuseador e o disco, que pode variar da percepção de cada indivíduo (técnico).

Na Tabela 2 podem ser observados os resultados das análises físico-químicas das 40 amostras coletadas na área de estudo. Além desses, foram constadas ausência de E. coli em todas as amostras e presença de coliformes totais apenas na amostra 25 .

Tabela 2 - Valores dos parâmetros físico-químicos analisados nas amostras de água coletadas.

\begin{tabular}{|c|c|c|c|c|c|c|c|c|c|c|c|}
\hline Ponto & $\begin{array}{c}\text { Turbidez } \\
\text { (UT) }\end{array}$ & $\mathrm{pH}$ & $\begin{array}{c}\text { CE }(\mu S / \\
\mathrm{cm})\end{array}$ & $\begin{array}{c}\text { Fluoreto } \\
(\mathrm{mg} / \mathrm{L})\end{array}$ & Setor & Ponto & $\begin{array}{c}\text { Turbidez } \\
\text { (uT) }\end{array}$ & $\mathrm{pH}$ & $\begin{array}{c}\mathrm{CE}(\mu \mathrm{S} / \\
\mathrm{cm})\end{array}$ & $\begin{array}{c}\text { Fluoreto } \\
\text { (mg/L) }\end{array}$ & Setor \\
\hline 1 & 0,92 & 7,60 & 126,7 & 0,59 & Pp. Ind & 21 & 0,84 & 6,90 & 92,1 & 0,66 & PT \\
\hline 2 & 0,58 & 7,50 & 122,7 & 0,57 & Pq. Ind & 22 & 1,18 & 7,00 & 90,6 & 0,61 & PT \\
\hline 3 & 0,70 & 7,30 & 119,0 & 0,61 & Pq. Ind & 23 & 0,95 & 7,40 & 123,0 & 0,23 & Vila Nova \\
\hline 4 & 0,58 & 7,50 & 126,7 & 0,63 & Pq. Ind & 24 & 0,36 & 7,40 & 124,1 & 0,23 & Vila Nova \\
\hline 5 & 0,48 & 7,50 & 122,5 & 0,60 & Pq. Ind & 25 & 0,57 & 7,40 & 123,8 & 0,26 & Vila Nova \\
\hline 6 & 0,44 & 7,30 & 120,9 & 0,58 & Pq. Ind & 26 & 0,51 & 7,40 & 121,5 & 0,40 & Vila Nova \\
\hline 7 & 0,70 & 7,30 & 120,8 & 0,55 & $\begin{array}{l}\text { Bairro } \\
\text { Feliz }\end{array}$ & 27 & 1,89 & 7,50 & 118,2 & 0,25 & Vila Nova \\
\hline 8 & 2,92 & 7,08 & 132,6 & 0,17 & SJT & 28 & 1,44 & 7,50 & 122,8 & 0,26 & Vila Nova \\
\hline 9 & 0,71 & 7,06 & 133,9 & 0,22 & SJT & 29 & 0,51 & 7,50 & 121,7 & 0,27 & Vila Nova \\
\hline 10 & 2,32 & 7,17 & 132,8 & 0,18 & SJT & 30 & 0,86 & 7,60 & 127,5 & 0,21 & Vila Nova \\
\hline 11 & 1,76 & 7,46 & 133,5 & 0,23 & SJT & 31 & 0,33 & 7,80 & 127,4 & 0,32 & Vila Nova \\
\hline 12 & 3,05 & 7,16 & 136,4 & 0,10 & SJT & 32 & 0,54 & 7,50 & 122,9 & 0,19 & Vila Nova \\
\hline 13 & 0,65 & 7,24 & 132,1 & 0,14 & SJT & 33 & 0,78 & 7,20 & 121,4 & 0,80 & Vila Nova \\
\hline 14 & 1,08 & 7,05 & 134,9 & 0,14 & SJT & 34 & 2,31 & 7,40 & 137,5 & 0,78 & Vila Nova \\
\hline 15 & 1,69 & 7,18 & 134,8 & 0,16 & SJT & 35 & 0,44 & 7,10 & 121,6 & 0,60 & Vila Nova \\
\hline 16 & 3,10 & 7,15 & 134,5 & 0,18 & SJT & 36 & 0,74 & 7,20 & 120,2 & 0,76 & Vila Nova \\
\hline 17 & 0,49 & 7,03 & 132,7 & 0,14 & SJT & 37 & 0,74 & 7,20 & 119,9 & 0,66 & Vila Nova \\
\hline 18 & 0,38 & 6,90 & 98,4 & 0,63 & PT & 38 & 1,12 & 7,20 & 119,7 & 0,77 & LU \\
\hline 19 & 3,44 & 6,80 & 92,1 & 00,56 & PT & 39 & 1,15 & 7,20 & 120,1 & 0,73 & LU \\
\hline 20 & 2,31 & 6,80 & 92,3 & 0,56 & PT & 40 & 5,25 & 7,40 & 140,7 & 0,73 & LU \\
\hline
\end{tabular}

Nota: Pq. Ind - Parque Industrial; SJT - São Judas Tadeu; PT - Parque Tramendão; LU - Leste Universitário. Fonte: o próprio autor

Para a turbidez, o limite máximo para qualquer amostra pontual deve ser de 5,0 uT em toda a extensão do sistema de distribuição incluindo reservatório e rede, sendo que na saída dos filtros o limite é de 0,5
uT (BRASIL, 2011). Para os pontos apresentados, apenas um ponto não atingiu a exigência da Portaria $n^{\circ}$ 2914/11, com valor de 5,25 uT, considerado valor atípico no boxplot (Figura 6a). Todos os valores de 
$\mathrm{pH}$, variando entre 6,8 e 7,8 (Figura 6b), estão de acordo com os valores entre 6,0 e 9,5 recomendando na Portaria $n^{0}$ 2914, da mesma forma que fluoreto, com valores entre 0,1 e $0,8 \mathrm{mg} / \mathrm{L}$ (Figura 6c), que também estão de acordo com a Portaria nº 2914/11, que estabelece o valor máximo permitido (VMP) de $1,5 \mathrm{mg} / \mathrm{L}$. O parâmetro CE não integra na Portaria $n^{\circ} 2914$ e, dessa forma, não apresenta limites, sendo que os resultados variaram de 90,6 e $140,7 \mu \mathrm{s} / \mathrm{cm}$ com 0,103 de coeficiente de variação.

Figura 6 - Variação dos parâmetros analisados nas amostras de água. Turbidez (a); pH (b) e Fluoreto (c).

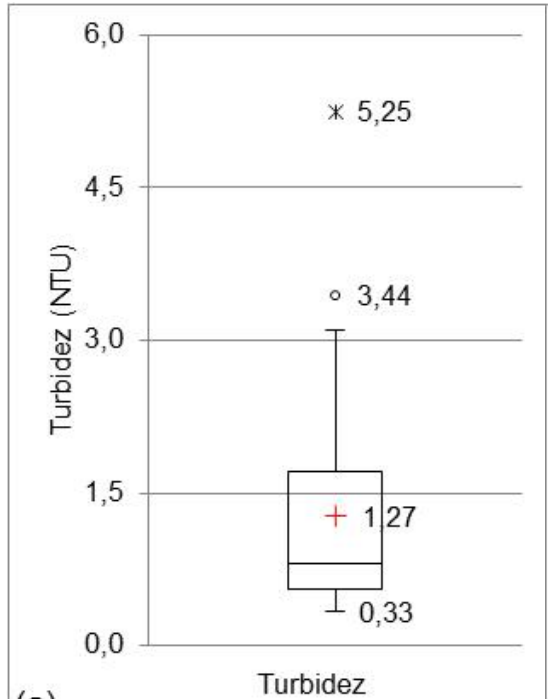

(a)

Fonte: o próprio autor

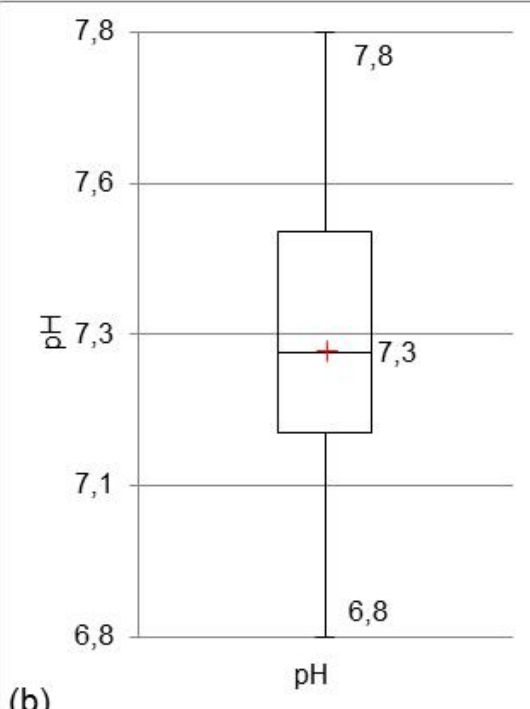

(b)

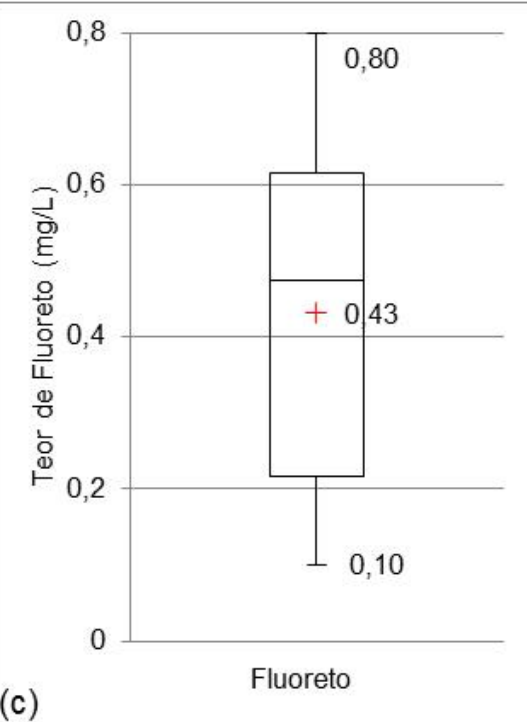

\section{Conclusões}

O presente trabalho permitiu concluir que os valores de cloro residual livre foram mais elevados quando utilizado o reagente DPD na forma em pó em comparação ao reagente DPD na forma de pastilha. Constatou-se também que os valores obtidos pelo equipamento visual foram superiores, com ambos os reagentes, em relação aos obtidos no equipamento digital. Foi existente uma interferência da turbidez sobre os resultados encontrados para cloro residual livre e também uma relação inversa entre o flúor e condutividade elétrica (correlação de -0,5442).

Conclui-se também que a utilização do método visual é mais prático para ser aplicado em campo. Por outro lado, é um método menos preciso por sofrer mais interferências, bem como, os erros do manuseador. No entanto, para as amostras analisadas as leituras nos dois métodos atenderam as exigências da Portaria n ${ }^{\circ} 2914 / 11$.
Recomendam-se pesquisas mais aprofundadas no quesito monitoramento do teor de cloro residual livre permitindo maior controle na sua dosagem, tornando-a mais precisa evitando o desperdício.

\section{Agradecimentos}

Os autores agradecem ao CNPq pela bolsa de iniciação científica concedida ao primeiro autor desse trabalho.

\section{Referências}

AMERICAN PUBLIC HEALTH ASSOCIATION - APHA; AMERICAN WATER WORKS ASSOCIATION - AWWA; WATER ENVIRONMENT FEDERATION - WEF. Standard methods for the examination of water and wastewater. $21^{\text {st. }}$ Washington: American Public Health Association; American Water Works Association; Water Environment Federation, 2005. 
ARAUJO, G. C.; ZEILHOFER, P. Padrões espaciais da qualidade da água na bacia do rio Cuiabá e rio São Lourenço-Mato Grosso. Hygeia, Chicago, v. 7 , n. 13, p. 55-70, 2011.

BRASIL. Ministério da Saúde. Portaria MS n²2914, de 12 de dezembro de 2011. Norma de qualidade da água para consumo humano. Brasília, 2011.

COMPANHIA AMBIENTAL DO ESTADO DE SÃO PAULO - CETESB. Guia nacional de coleta e preservação de amostras: água, sedimento, comunidades aquáticas e efluentes líquidos. São Paulo: CETESB; Brasília: ANA, 2011.

CHIRKES, J. D.; HEREDIA, O. S.; CIRELLI, A. F. Silicio y flúor en la llanura pampeana argentina. Disponivel em: <http://www.ina.gob.ar/ifrh-2014/ Eje2/2.05.pdf>. Acesso em: 27 abr. 2014.

DANIEL, L. A. (Coord.). Processos de desinfecção e desinfetantes alternativos na produção de água potável. São Carlos: Programa de Pesquisa em Saneamento Básico - PROSAB, 2001.

DI BERNARDO, L. Métodos e técnicas de tratamento de água. 2. ed. São Carlos: RiMa, 2005.

HELBLING, D. E.; VANBRIESEN, J. M. Free chlorine demand and cell survival of microbial suspensions. Water Research, New York, v. 41, n. 19, p. 4424-4434, 2007.

HORBE, A. M. C.; OLIVEIRA, L. G. S. Química de igarapés de água preta do nordeste do Amazonas - Brasil. Acta Amazonica, Manaus, v. 38, n. 4, p. 753-759, 2008.

MEYER, S. T. O uso de cloro na desinfecção de águas, a formação de trihalometanos e os riscos potenciais à saúde pública. Cadernos de Saúde Pública, Rio de Janeiro, v. 10, n. 1, p. 99-110, 1994.

NASCIMENTO, S. A. M.; ALVES, J. E. Estudo hidrogeoquímico comparativo entre os aquíferos Barreiras, Marizal e São Sebastião na região do Recôncavo Norte, Estado da Bahia. Cadernos de Geociências, Salvador, v. 11, n. 1-2, p. 72-82, 2014.

NOLL，R.; OLIVEIRA，I. L.; PESCADOR，J.
Avaliação de dois métodos concorrentes usado na determinação do cloro em água tratada. In: CONGRESSO INTERAMERICANO DE ENGENHARIA SANITÁRIA E AMBIENTAL, 27., 2000, Porto Alegre. Anais... Porto Alegre, 5p., 2000.

NORDSTROM, D. K; JENNE, E. A. Fluorite solubility equilibria in selected geothermal waters. Geochimica et Cosmochimica Acta, London, v. 41, n. 2, p. 175-188, 1977.

SAAD, B.; WAI, W. T.; JAB, S.; NGAH, W. S. W.; SALEH, M. I.; SLATER, J. M. Development of flow injection spectrophotometric methods for the determination of free available chlorine and total available chlorine: comparative study. Analytica Chimica Acta, Amsterdam, v. 537, n. 1-2, p. $197-$ 206, 2005.

SOUZA, J. B.; SARTORI, L.; DANIEL, L. A. Influência da cor e turbidez na desinfecção de águas de abastecimento utilizando-se cloro e radiação ultravioleta. In: CONGRESSO INTERAMERICANO DE ENGENHARIA SANITÁRIA E AMBIENTAL, 27., 2000, Porto Alegre. Anais... Porto Alegre, RS, 6p., 2000.

WILDE, E. W. Comparison of three methods for measuring residual chlorine. Water Research, New York, v. 25, n. 10, p. 1303-1305, 1991. http://dx.doi. org/10.1016/0043-1354(91)90071-W

WORLD HEALTH ORGANIZATION - WHO. Guidelines for drinking-water quality. 4. ed. Genebra: World Health Organization, 2011.

Recebido em 4 Maio, 2015 - Received on May 4, 2015 Aceito em 3 Setembro, 2015 - Accepted on September 3, 2015 
